\title{
Data Modelling in Human Resource Management: Influencing Factors of Employees' Job Satisfaction
}

\author{
Mei-Er Zhuang $\mathbb{D}^{1}$ and Wen-Tsao Pan $\mathbb{D}^{1,2}$ \\ ${ }^{1}$ Guangdong University of Foreign Studies, Guangzhou 510006, China \\ ${ }^{2}$ Hwa Hsia University of Technology, New Taipei 220, China \\ Correspondence should be addressed to Mei-Er Zhuang; 990883130@qq.com
}

Received 21 May 2021; Revised 23 December 2021; Accepted 6 January 2022; Published 8 February 2022

Academic Editor: Ali Ahmadian

Copyright (c) 2022 Mei-Er Zhuang and Wen-Tsao Pan. This is an open access article distributed under the Creative Commons Attribution License, which permits unrestricted use, distribution, and reproduction in any medium, provided the original work is properly cited.

\begin{abstract}
In the digital era, data mining and statistical analysis have been widely used to solve problems, especially in the field of management and engineering. Therefore, we aim to make a new insight of human resource management based on multiple regression modelling and quantile regression modelling. Specifically, the systematic framework of job satisfaction in this research is constructed by three dimensions from the perspective of psychology, namely, the perception of interpersonal relationship, financial compensation, and work conditions. Each dimension consists of two measures which reflect the employees' view towards them. The empirical estimation results show the following. (1) Perceived relationship with managers, perceived rationality of compensation, perceived match degree of job, and perceived autonomy degree of work are all significantly positively correlated with job satisfaction. (2) The effect of perceived rationality of compensation is significantly different between the high quantile and the low quantile. For those with lower perceived rationality of compensation, their job satisfaction is more likely to be affected due to the perceived compensation than those with higher perception. This research enriches the existing theory by constructing a comprehensive framework of the influencing factors of job satisfaction, which provides useful implications of human resource management optimization for enterprises.
\end{abstract}

\section{Introduction}

In the past decade, with the decline of birth rate and the intensification of population aging, China's demographic dividend has gradually faded. While the downward trend of global economy has resulted in unemployment for many workers, the shortage of labour supply for companies in different industries has been an increasingly obvious problem. Consequently, it has become a challenge for human resource management to attract adequate and capable employees and avoid losing labour assets. Braham [1] argues that employee turnover can lead to the cost of management and the damage of productivity.

It is of great importance to keep the appropriate employee retention as well as understand the reasons why employees disengage and leave their jobs. One possibility attributed to employee turnover is that employees are not only pulled by better offers but also pushed out of the company they are working in due to relatively low satisfaction [2]. Job satisfaction has been proved to have a significant relationship to organizational employee turnover and has generated widespread interest among researchers $[3,4]$. Thus, it is imperative to pay more attention to retaining employees by improving employee job satisfaction.

Job satisfaction has been defined in various ways. In a narrow sense, it mainly refers to the positive feelings and emotions from the appraisal of one's job or job experiences [5]. In a broad sense, job satisfaction can be regarded as the combination of psychological and environmental circumstances that arouses one's subjective reaction to all the issues pertaining to their jobs $[6,7]$. In this study, job satisfaction can be described as attitudes towards the perception between what one wants from one's job and what they actually gain from the job as offering or entailing [8]. 
Existing relevant research is mainly concentrated on the study of determinants and outcomes of job satisfaction from different perspectives, such as the influencing factors of job satisfaction and the effects of job satisfaction $[9,10]$. As for the latter, numerous literatures have reached a basically consistent conclusion, that is, job satisfaction has a positive impact on organizational performance through multiple channels. McNeese-Smith [11] indicated that employees with higher level of job satisfaction are likely to be more productive. The higher the job satisfaction is, the better the performance will be. Besides, the impacts of job satisfaction on performance are stable across time [12]. Since job satisfaction is conducive to higher performance, it is vital to have a deeper insight of the influencing factors of employees' job satisfaction, so that employees and employers can achieve better coordination by enhancing the employees' happiness and organizational performance.

Although much research has made contributions to the studies of job satisfaction, most of these previous research is restricted in developed economy or certain industries, lacking in establishing a framework to measure employee job satisfaction levels in a wider range [13]. It should be noted that studies have not clearly and systematically investigated the influencing factors of job satisfaction. Which specific aspects are important for job satisfaction may differ per countries or job type. China is one of the most influential emerging economies in the world. It is also a relation-oriented country with high power distance. According to Hofstede's cross-cultural theory, there are five cultural dimensions. Power distance is one of the dimensions and refers to the recognition of members of the society on the class difference caused by power and wealth [14]. China has unique cultural context which is greatly different from previous studies related to job satisfaction. Therefore, the purpose of this study is to identify the potential factors of job satisfaction in the context of China by applying a newly modified theoretical and structural framework.

\section{Literature Review}

A plethora of research has been published pertaining to employees' satisfaction including but not solely focused on personal characteristics, professional accomplishments, income, or their relationship with other staff [15]. According to the existing literature, a vast amount of research on the issue of job satisfaction has been documented based on different perspectives. Particularly, the influencing factors of job satisfaction can be divided into four categories: demographic characteristics, individual endowments, contextual situations, and psychological conditions [16, 17]. Demographic characteristics refer to basic attributes that cannot be changed manually such as gender [18] and age [19]. Individual endowments include educational background such as academic level or career-training experience [20] Contextual situations include work environment, communication atmosphere, compensation and benefits, insurance, and security [21]. Psychological conditions include adaptability and job stress [22]. Many studies have confirmed that these factors mentioned above have significant impacts on job satisfaction to some extent [23].

In addition to the above classification of factors affecting job satisfaction, there are also other classification methods or evaluations methods [24]. Some scholars proposed that the determinants of job satisfaction can be grouped into three categories according to the perspectives of personal characteristics, job characteristics, and organizational characteristics, while others argued that the determinants should be divided into two kinds, namely, endogenous intrinsic factors and exogenous extrinsic factors $[25,26]$. On the one hand, the combination of endogenous psychological factors is regarded as a closed system, such as psychological contract, sense of support, trust, emotional intelligence, and mental health [27]. It mainly integrates individual characteristics, focusing on the role of psychological determinants from a deeper internal perspective [28]. On the other hand, the combination of exogenous factors is regarded as an open system, focusing on the work conditions and social environment perspective [29]. Studies related to the exogenous factors mainly demonstrate the effect of work atmosphere, leadership style, professional positions, or working hours on job satisfaction. For example, common environmental stressors in the work environment can be stressful to staff and influence job satisfaction [30, 31].

Research on job satisfaction has been developing greatly in the past few decades, but it remains unclear which types of determinants exert most effects on the employees' attitude partly because the traditional framework lacked multidimensional analysis. Due to the complication of the mechanism between job satisfaction and influencing factors, related determinants have not been fully explored and validated up to now, which provides the research gap and the reason why more investigation is needed to make a deeper insight on this field.

Therefore, making the most of the paradigm of endogenous and exogenous research, we construct a more comprehensive framework of job satisfaction from the perspective of both endogenous and exogenous factors. Based on the individual perception of employees, we set up two-level variables for analysis on the secondary indicators in each dimension. Specifically, we focused on the following dimensions: interpersonal relationship, financial compensation, and work conditions. In each dimension, we construct two variables involving the perception of employees as the determinants of job satisfaction.

Drawing on the data of Chinese General Social Survey (CGSS), we extracted variables that meet these three dimensions for empirical analysis and explored the estimation effects of these six factors on job satisfaction to clarify the mechanism, thereby creating a more comprehensive explanation of the relationship between the three-dimensional determinants and job satisfaction.

\section{Hypothesis Development}

3.1. Interpersonal Relationship. Interpersonal relationship of employees in the workplace can be subdivided into two categories, namely, the relationship with managers and the 
relationship with colleagues [32]. Managers in this context mainly include supervisors, team leaders, and any superiors that have a higher position level than the employee themselves in the organization while the colleagues refer to those co-workers that are in the same or similar position level in the organization.

Relationship may have a "double-edged sword" effect on employees' performance. Individual-level relationship may increase job satisfaction and performance, while group-level relationship may weaken employees' sense of procedural justice and reduce their work performance [33]. Relationship with supervisors and colleagues has been estimated to have significant influence on job satisfaction in different fields such as healthcare industry [34]. Employees who are from dominant groups in the organization tend to be more satisfied with their jobs because their managers and coworkers tend to provide them with more feedback and support [35]. Scholars have also revealed that employees at the establishment career stage are more likely to expect to become accepted as equal and regular members of the organization by building an effective relationship with coworkers and supervisors, thus learning organizational norms and values better [36]. Although research on social decision making has already shown that trust on a third party affects the individual's cooperative behavior [37], studies have suggested that employees' perception of both co-workers and supervisory support may bring different outcomes, which means that employees' trust towards their co-workers and supervisors varies in general working place [38]. Hence, interpersonal relationship with managers and colleagues may influence employees' perception differently.

On the one hand, perceived relationship with managers can be defined as a kind of supervisor-subordinate relation based on employees' perception of interaction with leaders and supervisors [39]. According to Hofstede's theory, China's power distance gap is relatively huge and the concentration degree and dictatorship degree of power in Chinese society are high. Furthermore, leadership behaviors can vary over two domains according to the leadership theory proposed by Hersey and Blanchard [40]: task-oriented and relation-oriented leadership behaviors. China is a typical relation-oriented society where informal systems often play a potentially huge role. Hence, specific leadership behaviors such as coordinating and structuring and also how supervisors communicate may have more significant impacts on employee job satisfaction [41]. For example, from the frontline staff perspective, if managers fail to provide constant support and understanding, they will perceive a poor leadership that undermines their trust and job satisfaction [42]. As the director of power and the distributor of resources, leaders have the right to determine the allocation of resources in the organization and may be closely related to the vital interests of each employee, which means that getting the appreciation of leadership is particularly important [43]. If employees have a better relationship with managers who have dominant power and resources, they may have potential competitive advantages in terms of resource acquisition and benefit distribution, which is conducive to gaining opportunities for career development [44]. This can account for the reason why employees that perceived their relationships with supervisors more positive show greater levels of job satisfaction than those who do not hold such beliefs [45]. In that case, employees getting along well with managers may have more self-belief and even a sense of superiority, so their job satisfaction will be correspondingly higher [46].

Therefore, the first hypothesis is proposed as follows.

H1a: perceived interpersonal relationship with managers has a positive effect on job satisfaction.

On the other hand, perceived relationship with colleagues refers to the peer relation of co-workers that are in the same or similar position level in the organization, represented by friendliness and kindness from colleagues. Studies have found that co-worker support is considered to be predictors of the employees' behavior [47]. However, such influences may differ with different genders, and studies have proved that perceived co-worker support was more strongly related to organization commitment which is typical outcome of job satisfaction for women than for men [48]. Relationships with colleagues are mutually supportive in a situation where co-workers are cooperative and work collaboratively. Co-worker support was significantly related to personal accomplishment [49]. Those having good interpersonal relationship with colleagues are also easier to overcome difficulties due to knowledge sharing when they encounter challenges at work. Employees experienced close and friendly relationship in the occupational team as a source of strength that enabled them to overcome different hurdles [50]. In other words, when faced with trouble, those having co-worker support are more likely to obtain enough valuable information and timely help, so that they are more likely to find a solution to the problem in a shorter time, which helps to increase the probability of success, thereby generating more positive emotions and improving job satisfaction [51]. Otherwise, when relationships with colleagues were strained, employees' ideas and creativity would be hindered, which may harm their job satisfaction [52]. Research has also been shown that teamwork was positively associated with job satisfaction by creating positive interaction. Good interpersonal relationship with colleagues may help to form a closer emotional connection [53]. When employees are in a bad mood and need care, they are more likely to be comforted by colleagues if they have good interpersonal relationship, which can reduce depression and conflicts in workplace [54]. Such a good state of interpersonal relationship may have an impact on the effectiveness and efficiency of communication, social exchanges, and emotional venting among employees and contributes to carry out more harmonious cooperation and form a good working atmosphere [55]. Good atmosphere created a supportive environment and a sense of safety and security, which can reduce the pressure of life and work to a certain extent [56]. When one felt supported and backed by colleagues, their job satisfaction may be well improved. 
Therefore, the second hypothesis is proposed as follows. H1b: perceived interpersonal relationship with colleagues has a positive effect on job satisfaction.

3.2. Financial Compensation. Compensation refers to the salaries, income, rewards, insurance, and any monetary payment and financial benefits employees received from their jobs. Earlier studies believed that compensation did not have a significant impact on job satisfaction $[57,58]$. In some studies related to hotel internship program, researchers found that compensation composed of overtime pay, fringe and benefits, and salary did not significantly affect internship satisfaction $[59,60]$.

However, more and more studies have argued that compensation level is positively correlated with job satisfaction, which can be explained by the resource preservation theory $[61,62]$. In their research, improvement in compensation represents an increase in the material resources occupied by employees. Psychological motivation of employees would be enhanced, thus accumulating higher job satisfaction [63]. Some other scholars also show convincing evidence of the assumption that stable income is important for the attractiveness of job [64].

Nevertheless, some scholars held different views and presented opposite conclusions, suggesting that salary level is negatively correlated with job satisfaction [65]. Besides, some complicated mechanism may be existing in the relationship between compensation and job satisfaction. For example, it could be a type of nonlinear relationship, which can be described as "inverted U-shaped" curve [66]. These diverse and seemingly contradictory research results reflect the fact that the relationship between compensation and job satisfaction is complex and still needs further investigation.

On the one hand, perceived rationality of compensation can be defined as the perception and judgment of compensation based on their ability and expectations. Numerous studies have suggested that perceptions of fairness play a vital role in the service encounter [67]. Studies highlight how compensation can influence their job satisfaction [68]. When exploring the effects of compensation, most of the existing studies are value-oriented and merely focus on the amount of compensation rather than the perception of employees. In fact, the perception of income and the specific value of income are not equal. In other words, perception of compensation is not the same as the amount of compensation itself, which should not be ignored. On the basis of Adam's [69] equity theory, job satisfaction can be determined by the employee's input-income ratio and those of the referents. The level of an employee's job satisfaction may be affected by the assessment based on their own contribution and compensation [70].

Thus, the employee's subjective assessment of his or her input-related reward can determine his or her job satisfaction [71]. If people with average incomes feel that their income is inadequate and does not reach a proper level they should be, their perceived rationality of compensation becomes weak, and then their job satisfaction may be relatively low. On the contrary, for people whose income level is not very high, if they believe that their income is in line with their own contribution and meets their expectations, then their sense of reasonableness of income will be strong, which may be easier to arouse a stronger feeling of job satisfaction.

In short, the perception of reasonableness of compensation is not equal to the absolute value of compensation and the higher perceived rationality of compensation may have a positive impact on job satisfaction. Therefore, it is necessary to distinguish the absolute value of compensation from the perceived rationality of compensation.

Therefore, the third hypothesis is proposed as follows.

$\mathrm{H} 2 \mathrm{a}$ : perceived rationality of compensation has a positive effect on job satisfaction.

On the other hand, the level of an employee's job satisfaction can also be affected by a comparison with the contribution and financial compensation of others. Previous theory claims that people's job satisfaction is not only related to personal absolute compensation but also more closely related to people's sense of fairness and equity in distribution [72].

Perceived equity of distribution can be defined as the perception of fairness of the job compensation, which is the subjective judgment of the employees on the fairness of the organization's resource distribution [73]. Studies have shown that both the external fairness and internal fairness of compensation will have a significant impact on employee job satisfaction [74]. In other words, an employee may feel a psychological conflict associated with his or her compensation when an equivalent colleague receives a higher income, and this discrepancy can decrease the employee's job satisfaction. McLoughlin and Carr [75] suggested that employees tend to be less satisfied with their job because of the inequalities they experience in rewards.

Perceived equity of distribution is important, and it is reported that equal and fair compensation system positively influences job satisfaction of a multicultural workforce [76]. Research suggested that fairness of salary in centralized public procurement systems is the key factor of job satisfaction [77].

However, the relationship between perceived equity of distribution and job satisfaction in the context of Chinese workplace has not been fully estimated.

Therefore, the fourth hypothesis is proposed as follows.

$\mathrm{H} 2 \mathrm{~b}$ : perceived equity of distribution has a positive effect on job satisfaction.

3.3. Work Conditions. Work conditions mainly refer to the combination of objective and subjective issues related to workload, working period, workplace environment, promotion opportunity, and work stress [78]. In our study, we focus on two important components of work conditions, namely, perceived match between ability and job [79] and perceived autonomy [80].

Person-job fit is defined as a match between individual knowledge, skills, abilities, and the job requirements [81]. It is usually presented as the compatibility between the employee and the tasks that are expected to be accomplished in exchange for employment $[82,83]$. 
Researchers suggested that employees' work attitude was affected by the perceived person-organization fit [84]. In an analysis for female managers, scholars found that the higher the individual-organization matching is, the more the job satisfaction would be [85]. The lower person-job match represented by the perception of overqualification of employees would cause employees to feel frustrated because the work they are engaged in cannot give full play to their own skills, which makes them more likely to lose interest in work [86].

To be more specific, we use the term "match degree of ability" to depict the degree to which employees' job fits his or her ability. A high match degree of ability indicates that the knowledge and skills required for a given job are highly related to those provided by their education, experience, and abilities [87]. In such situations, job-related knowledge is strongly associated with potential job performance and may affect job satisfaction. Otherwise, when employees' previous knowledge or skills cannot be applied in the existing work fully or when the employees feel that they have difficulties in adapting to the current job or exerting their original talents and experience on the work task, there will be a sense of mismatch, resulting in lower job satisfaction. Lawler [88] suggested that if employees perceive that reward allocation is unfair or unrelated to the level of employee contribution, it would not be possible to sustain-in the long run-managerial practices based on empowerment. Under those conditions, employee motivation would decrease and interest towards empowerment would eventually be eroded [89]. Even if some employees have good qualifications, the mismatch between employees' occupation and their abilities may still lead to relatively worse performance to some extent, thus causing the lack of self-confidence and job satifaction.

Therefore, the fifth hypothesis is proposed as follows.

$\mathrm{H} 3 \mathrm{a}$ : perceived match degree of ability has a positive effect on job satisfaction.

On the other hand, autonomy degree of work provides another indicator of the source of employee satisfaction in terms of work conditions [90]. Hackman and Oldham [91] defined job autonomy as the degree to which the job provides substantial freedom, independence, and discretion to the employee in scheduling the work and in determining the procedures to be used in carrying it out. In other words, autonomy degree of work can be defined as the level of freedom employees experience in terms of decision making at the workplace [92]. In this study, we use the term "autonomy degree of work" to depict the degree to which the job provides freedom and independence for employees' developments and work-life balance.

Self-determination theory believes that people have basic psychological needs for autonomy, sense of belonging and relatedness, and competence. When good working conditions are provided and the three innate needs are met, employees are more likely to work under the drive of internal motivation, thus exerting their potential and creating positive work performance. Employees who believe they have greater autonomy to make decisions at work are also shown to be more satisfied with their jobs [93]. The domain of autonomy is reflected in conflicts which arise from leadership style, management practices, and decisionmaking processes. Job autonomy is aligned with job resource which seeks to prevent the negative impact job demands will bring. While job demands concern themselves with the cost in physiology, social, psychological, or organizational sides of the job like emotional demands, job resources lessen the impact of job demands and their costs to stimulate some level of learning, growth, and development. Therefore, absence of job autonomy raises the negativities of absenteeism, stress, repetitive strain, and ill health, whereas presence of job autonomy leads to higher employee job satisfaction [94].

Research on the influence mechanism of job autonomy on job satisfaction has been quite consistent. Findings have mostly suggested that job autonomy leads to job satisfaction on the same assumption. A lack of autonomy will result in higher levels of stress which in turn can lead to dissatisfaction in one's work [95].

It has been confirmed that autonomy in work process [96], flexible working hours [97], and autonomy in workload [98] all have positive impacts on satisfaction. Studies have shown that working hours affect job satisfaction by changing employee perceptions of work context [99]. Some scholars have pointed out that flexible work plans can significantly reduce employees' work-family conflict and turnover tendency and improve perceived job autonomy, job satisfaction, organizational commitment, and job performance [100]. Compatibility between family life and working hours, namely, the reduction of conflicts between work and leisure time, is clearly conducive to satisfaction [101]. It can be inferred that work-life balance contributes to job satisfaction while unsatisfactory working conditions lead to work-family conflicts, time pressure, emotional exhaustion, and time stress, which ultimately result in high turnover rates [102].

Based on the analysis, it can be inferred that if the employers enhance the autonomy and freedom of employees and support them in arranging their time and work tasks reasonably, it can largely alleviate the time conflicts of employees at work, thereby enhancing work flexibility degree and adaptability, which improves the job satisfaction of employees.

Therefore, the sixth hypothesis is proposed as follows.

$\mathrm{H} 3 \mathrm{~b}$ : perceived autonomy degree of work has a positive effect on job satisfaction.

The research framework is shown as Figure 1.

\section{Research Method}

4.1. Model Construction. Based on the three dimensions of determinants of job satisfaction, namely, interpersonal relationship, financial compensation, and work conditions, a regression model is established as follows:

$$
\begin{aligned}
\mathrm{JS}= & \beta_{0}+\beta_{1} \mathrm{MANAG}+\beta_{2} \text { COLLEA }+\beta_{3} \text { RATION } \\
& +\beta_{4} \text { EAUITY }+\beta_{5} \mathrm{MATCH}+\beta_{6} \mathrm{AUTON}+\varepsilon .
\end{aligned}
$$

On the left side, JS represents the dependent variable, namely, job satisfaction. On the right side, six independent variables are represented by acronyms. To be more specific, MANAG stands for relationship with 


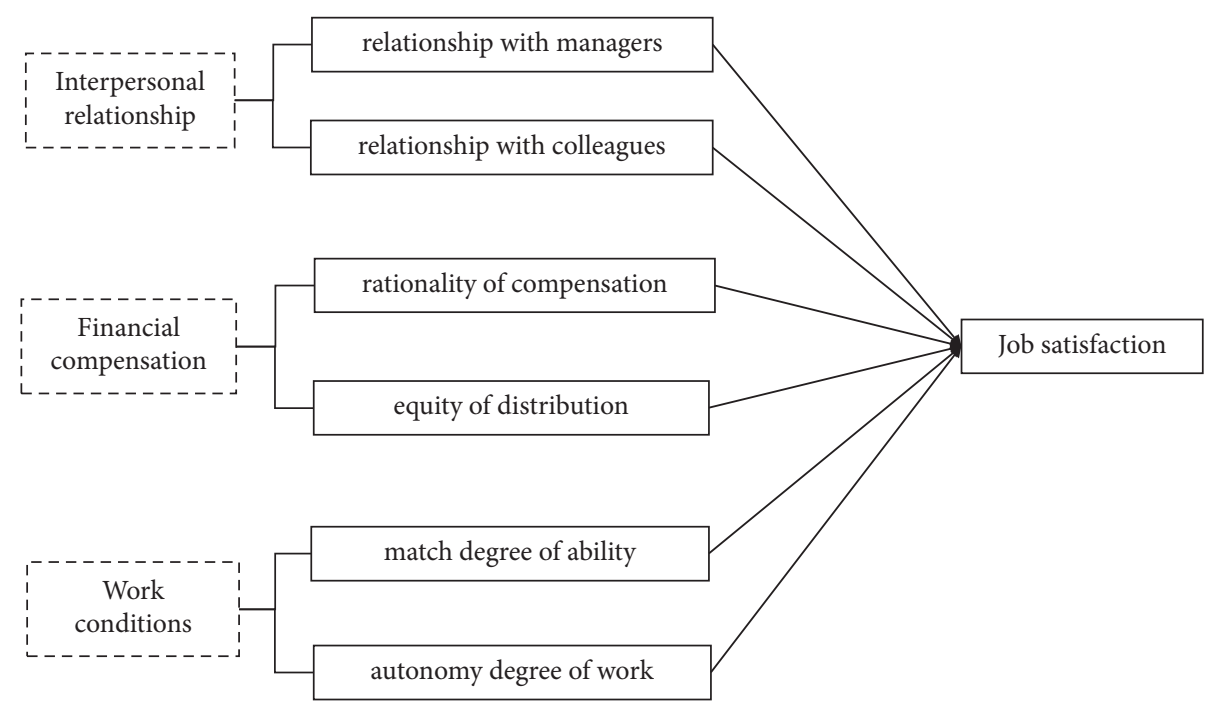

Figure 1: Research framework.

managers, and COLLEA stands for relationship with colleagues. RATION is represented by perceived rationality of compensation. EQUITY stands for perceived equity of distribution, and MATCH stands for perceived match degree of job. AUTON stands for perceived autonomy degree of work. $\beta_{1}, \beta_{2} \ldots \beta_{6}$ are the corresponding regression coefficients. $\beta_{0}$ is a constant term, and $\varepsilon$ represents the random error.

4.2. Data Source. Drawing on the data form Chinese General Social Survey (CGSS), we select and construct the corresponding scale to measure the variables and conduct empirical analysis to test the hypotheses. CGSS is China's first national and continuous large-scale social survey project. CGSS aims to collect data from Chinese people and all aspects of Chinese society regularly and systematically, summarizing the long-term trend of social change. The main purpose is to explore social issues of great theoretical and practical significance and promote the openness and sharing of domestic social science research.

Up to now, the sample data in CGSS in 2015 are considered the latest version of the project. CGSS 2015 adopts random sampling method covering 28 provinces (excluding Tibet, Xinjiang, Hainan, Hong Kong, Macao, and Taiwan). It is worth noting that 10968 residents from 478 natural villages and 83 prefecture-level cities were interviewed across 130 counties and 369 townships, which makes the sample size very large and convincing. Content of the questionnaire of CGSS 2015 not only includes the description of objective characteristics but also includes subjective questions, which is suitable for the requirements of this research.

4.3. Measures. The method of preprocessing of the raw data and the detailed descriptive information of each item in the scale are introduced in this section (see Table 1).
There are three steps in the preprocessing. First, remove missing values and invalid data. As some interviewees did not fill in all the questionnaire, some of the data were incomplete. Therefore, invalid samples with missing values in the key variables must be eliminated to ensure the scientific and rigorous data analysis. Second, since the CGSS2015 questionnaire is divided into several modules and some of the questions in some modules are only for specific groups of participants, the applicable objects of each question are not completely the same. The items we need for this research originated from module A, module B, and module D. However, module A and module B are full samples of 10968 because those participants can answer all the questions, while module D has only part of the interviews for the reason that some of them are not suitable for the questionnaire, which means that the data sample size extracted from the three modules of CGSS 2015 is quite different. In order to ensure the accuracy of the empirical analysis, the data need to be matched and paired. The specific method is based on whether the D module of the questionnaire is answered or not. Those corresponding samples that did not answer question related to job satisfaction are eliminated, and only those valid samples that have answered the main questions at the same time are retained, so that the sample size of each question item is basically balanced. Third, we processed the control variables including gender and education level in the social demographic attributes. We construct 0-1 dummy variable for gender and education level.

\section{Result Analysis}

Stata is used to conduct empirical estimation on sample data. First, the descriptive statistics are demonstrated, followed by the correlation analysis. Then, hypothesis testing is conducted through multiple regression, and 
TABLE 1: Scales and items of variables.

\begin{tabular}{|c|c|c|}
\hline Variables & Items & Scales \\
\hline JS & Are you satisfied with your current job? & $\begin{array}{c}\text { This question is rated using a 5-point Likert-type scale format. } 1=\text { "very } \\
\text { satisfied," } 2=\text { "satisfied," } 3=\text { "neutral," } 4=\text { = "dissatisfied," and } 5=\text { "very } \\
\text { dissatisfied" }\end{array}$ \\
\hline MANAG & $\begin{array}{l}\text { What do you think of your relationship with } \\
\text { your managers? }\end{array}$ & $\begin{array}{l}\text { This question is rated using a 5-point Likert-type scale format. } 1=\text { "very } \\
\text { good," } 2=\text { "good," } 3=\text { "neutral," } 4=\text { = "bad," and } 5=\text { "very bad" }\end{array}$ \\
\hline COLLEA & $\begin{array}{l}\text { What do you think of your relationship with } \\
\text { your colleagues? }\end{array}$ & $\begin{array}{l}\text { This question is rated using a 5-point Likert-type scale format. } 1=\text { "very } \\
\text { good," } 2 \text { ="good," } 3=\text { "neutral," } 4=\text { ="bad," and } 5=\text { "very bad" }\end{array}$ \\
\hline RATION & $\begin{array}{l}\text { Considering your abilities and work status, is } \\
\text { your current income reasonable? }\end{array}$ & $\begin{array}{l}\text { This question is rated using a } 4 \text {-point Likert-type scale format. } 1=\text { "very } \\
\text { reasonable," } 2=\text { "reasonable," } 3=\text { "unreasonable," and } 4=\text { "very } \\
\text { unreasonable" }\end{array}$ \\
\hline EQUITY & $\begin{array}{l}\text { Do you think the social distribution method is } \\
\text { fair? }\end{array}$ & $\begin{array}{l}\text { This question is rated using a 5-point Likert-type scale format. } 1 \text { = "very fair," } \\
2=\text { "fair," } 3=\text { "neutral," } 4=\text { "unfair," and } 5=\text { "very unfair" }\end{array}$ \\
\hline MATCH & $\begin{array}{l}\text { How much of your past work experience/or } \\
\text { skills can be used in your current work? }\end{array}$ & $\begin{array}{l}\text { This question is rated using a 4-point Likert-type scale format. } 1=\text { "very } \\
\text { little," } 2=\text { "a little bit," } 3 \text { = "some," and } 4 \text { = "very much" }\end{array}$ \\
\hline AOTON & How is your daily work schedule? & $\begin{array}{l}\text { This question is rated using a 3-point Likert-type scale format. } 1=\text { "free," } \\
2 \text { ="neutral," and } 3 \text { ="fixed" }\end{array}$ \\
\hline Controls & $\begin{array}{c}\text { Gender (GEN) } \\
\text { Education level (EDU) }\end{array}$ & $\begin{array}{l}\text { Female }=0 ; \text { male }=1 \\
\text { Senior high school and above }=0 ; \text { junior high school and below }=1\end{array}$ \\
\hline
\end{tabular}

finally the robustness check through quantile regression modelling is illustrated.

5.1. Descriptive Statistics. According to statistics, the gender ratio of the sample is basically balanced, with $49.23 \%$ of women and $50.77 \%$ of men. In terms of educational level, the proportion of people with higher education background is slightly smaller. Nearly $47 \%$ of participants graduated from high school or have a higher degree.

As shown in Table 2, the variance inflation factor (VIF) of each explanatory variable is very small, and the mean value of variance inflation factor is 1.39 , indicating that there is no multicollinearity problem in the variables. The mean value of MANAG is about 3.4, indicating that the sample's perception of the manager's relationship is roughly at the upper-middle level. The mean of the variables COLLEA, RATION, and EQUITY is in the range of 2.0 to 2.3 , indicating that the sample's perception of these issues is relatively worse. The mean of the variable MATCH is about 3.1, reflecting that more interviewees think that some of their work experience and skills can be applied to the current jobs. The mean of that measure is about 2.5 , which is close to the highest value of this question. Due to the negative rating of the question related to AOTON, most of the sample respondents showed that they cannot freely decide their daily work arrangements.

In addition, variables in this study have high standard deviations (SDs), indicating that the measurement method used in the sample is effective, and the heterogeneity in the selected variables is also obvious.

5.2. Correlation Analysis. Before regression analysis, we conducted a preliminary analysis of the correlation between each independent variable and the dependent variable. It can be seen from the second column of Table 3 that in the case of univariate analysis, except for the control variable of gender, the other variables are all significantly correlated with the dependent variable at the $5 \%$ statistical level. Since the rating rules of the two variables EQUITY and MATCH are opposite to the rules of other dependent variable, the negative sign before the coefficient of EQUITY and MATCH represents a positive correlation actually. In other words, from the results of the correlation analysis, the dependent variable is significantly positively correlated with all independent variables, and they are all positively correlated. However, correlation analysis is not enough to confirm whether there is a robust causal relationship between variables. Therefore, multiple regression analysis is needed to estimate the parameters.

5.3. Multiple Regression Modelling. As shown in Table 4, we use stepwise multiple regression to test all hypotheses separately. From columns (1), (4), (5), and (7), the regression coefficient of MANAG is positive at the significance level of $1 \%$, which indicates that the better the employee's perception of the relationship with managers, the higher the satisfaction level, so hypothesis $\mathrm{Hla}$ is verified. On the other hand, regression coefficient of COLLEA is not significant, indicating that the perceived relationship with colleagues may not have such a strong impact on job satisfaction. Hypothesis H1b cannot be supported.

From columns (2), (5), (6), and (7), regression coefficient of RATION is significant at the $1 \%$ statistical level, indicating that the more reasonable the employee's perceived compensation is, the higher the satisfaction level is. Hypothesis $\mathrm{H} 2 \mathrm{a}$ is verified.

However, the regression coefficient of EQUITY is not significant, indicating that the effect of distribution fairness on job satisfaction is not so obvious as expected. Hypothesis $\mathrm{H} 2 \mathrm{~b}$ has not been supported. 
TABLE 2: Descriptive statistics and multicollinearity diagnosis.

\begin{tabular}{lccccc}
\hline Variables & $N$ & Mean & SD & VIF & 1/VIF \\
\hline MANAG & 782 & 3.337596 & 1.059603 & 2.13 & 2.11 \\
COLLEA & 506 & 2.23913 & 0.6837074 & 1.05 & 0.469180 \\
RATION & 511 & 2.064579 & 0.6460572 & 1.04 & 0.952748 \\
EQUITY & 758 & 2.340369 & 0.5417627 & 1.02 & 0.958860 \\
MATCH & 778 & 3.120823 & 1.004906 & 0.977118 \\
AOTON & 765 & 2.508497 & 0.9089396 & 1.01 & 0.988677 \\
\hline
\end{tabular}

TABLE 3: Correlation analysis results.

\begin{tabular}{|c|c|c|c|c|c|c|c|c|c|}
\hline Variables & JS & MANAG & COLLEA & RATION & EQUITY & MATCH & AOTON & GEN & EDU \\
\hline JS & 1 & & & & & & & & \\
\hline MANAG & $0.279^{*}$ & 1 & & & & & & & \\
\hline COLLEA & $0.246^{*}$ & $0.722^{*}$ & 1 & & & & & & \\
\hline RATION & $0.336^{*}$ & 0.042 & 0.029 & 1 & & & & & \\
\hline EQUITY & $-0.104^{*}$ & 0.013 & -0.028 & $-0.201^{*}$ & 1 & & & & \\
\hline MATCH & $-0.086^{*}$ & -0.084 & -0.051 & -0.019 & 0.022 & 1 & & & \\
\hline AOTON & $0.160^{*}$ & $0.132^{*}$ & $0.101^{*}$ & $0.095^{*}$ & 0.002 & -0.035 & 1 & & \\
\hline GEN & -0.073 & 0.004 & 0.010 & -0.049 & 0.054 & 0.040 & $-0.099^{*}$ & 1 & \\
\hline EDU & $0.156^{*}$ & 0.035 & 0.013 & 0.022 & 0.010 & -0.058 & $-0.102^{*}$ & -0.009 & 1 \\
\hline
\end{tabular}

Note. ${ }^{*}$ denotes the significance level at $5 \%$ ( ${ }^{*}$ means $\left.P \leq 0.05\right)$.

TABLE 4: Multiple regression analysis results.

\begin{tabular}{|c|c|c|c|c|c|c|c|}
\hline \multirow{2}{*}{ Variables } & \multicolumn{7}{|c|}{ JS } \\
\hline & $(1)$ & $(2)$ & (3) & $(4)$ & (5) & (6) & $(7)$ \\
\hline MANAG & $\begin{array}{c}0.294^{* * *} \\
(0.089)\end{array}$ & & & $\begin{array}{c}0.248^{* * *} \\
(0.088)\end{array}$ & $\begin{array}{c}0.279^{* * *} \\
(0.083)\end{array}$ & & $\begin{array}{c}0.246^{* * *} \\
(0.082)\end{array}$ \\
\hline COLLEA & $\begin{array}{c}0.144 \\
(0.095)\end{array}$ & & & $\begin{array}{c}0.167 \\
(0.093)\end{array}$ & $\begin{array}{c}0.130 \\
(0.089)\end{array}$ & & $\begin{array}{c}0.151 \\
(0.087)\end{array}$ \\
\hline RATION & & $\begin{array}{c}0.625^{* * *} \\
(0.068)\end{array}$ & & & $\begin{array}{c}0.661^{* * *} \\
(0.074)\end{array}$ & $\begin{array}{c}0.679^{* * *} \\
(0.073)\end{array}$ & $\begin{array}{c}0.622^{* * *} \\
(0.073)\end{array}$ \\
\hline EQUITY & & $\begin{array}{l}-0.038 \\
(0.037)\end{array}$ & & & $\begin{array}{l}-0.060 \\
(0.040)\end{array}$ & $\begin{array}{c}-0.048 \\
(0.040)\end{array}$ & $\begin{array}{l}-0.073 \\
(0.040)\end{array}$ \\
\hline MATCH & & & $\begin{array}{c}-0.170^{* * *} \\
(0.046)\end{array}$ & $\begin{array}{c}-0.175^{* * *} \\
(0.048)\end{array}$ & & $\begin{array}{c}-0.146^{* * *} \\
(0.044)\end{array}$ & $\begin{array}{c}-0.147^{* * *} \\
(0.045)\end{array}$ \\
\hline AOTON & & & $\begin{array}{c}0.197^{* * *} \\
(0.056)\end{array}$ & $\begin{array}{c}0.171^{* * *} \\
(0.060)\end{array}$ & & $\begin{array}{c}0.154^{* * *} \\
(0.053)\end{array}$ & $\begin{array}{c}0.127^{* *} \\
(0.056)\end{array}$ \\
\hline GEN & $\begin{array}{l}-0.110 \\
(0.085)\end{array}$ & $\begin{array}{c}-0.119^{*} \\
(0.072)\end{array}$ & $\begin{array}{c}-0.108 \\
(0.083)\end{array}$ & $\begin{array}{r}-0.069 \\
(0.083)\end{array}$ & $\begin{array}{l}-0.073 \\
(0.079)\end{array}$ & $\begin{array}{r}-0.076 \\
(0.078)\end{array}$ & $\begin{array}{l}-0.044 \\
(0.078)\end{array}$ \\
\hline EDU & $\begin{array}{c}0.049 \\
(0.088)\end{array}$ & $\begin{array}{c}0.308^{* * *} \\
(0.072)\end{array}$ & $\begin{array}{c}0.120 \\
(0.085)\end{array}$ & $\begin{array}{c}0.014 \\
(0.088)\end{array}$ & $\begin{array}{c}0.058 \\
(0.082)\end{array}$ & $\begin{array}{c}0.096 \\
(0.080)\end{array}$ & $\begin{array}{c}0.032 \\
(0.082)\end{array}$ \\
\hline Constant & $\begin{array}{c}2.280^{* * *} \\
(0.161)\end{array}$ & $\begin{array}{c}1.884^{* * *} \\
(0.222)\end{array}$ & $\begin{array}{c}3.231^{* * *} \\
(0.187)\end{array}$ & $\begin{array}{c}2.387^{* * *} \\
(0.241)\end{array}$ & $\begin{array}{c}0.966^{* * *} \\
(0.272)\end{array}$ & $\begin{array}{c}1.811^{* * *} \\
(0.283)\end{array}$ & $\begin{array}{c}1.205^{* * *} \\
(0.312)\end{array}$ \\
\hline$N$ & 502 & 752 & 576 & 491 & 491 & 559 & 481 \\
\hline$R^{2}$ & 0.082 & 0.138 & 0.054 & 0.127 & 0.227 & 0.195 & 0.259 \\
\hline
\end{tabular}

Note. The numbers in brackets are robust standard errors. ${ }^{*},{ }^{* *}$, and ${ }^{* * *}$ represent the significance level at $10 \%, 5 \%$, and $1 \%$, respectively $\left({ }^{*}\right.$ means $P \leq 0.1$, ${ }^{* *}$ means $P \leq 0.05$, and ${ }^{* * *}$ means $P \leq 0.01$ ).

From columns (3), (4), (6), and (7), regression coefficients of MATCH and AOTON are both significant at the $1 \%$ statistical level, indicating that the perception of job match and autonomy both have significant impacts on job satisfaction. Hypotheses $\mathrm{H} 3 \mathrm{a}$ and $\mathrm{H} 3 \mathrm{~b}$ have been verified.

\section{Discussion of the Basic Regression Results}

Based on the results of basic regression, it can be found that whether interpersonal relationships will affect employees' job satisfaction depends on the specific types of interpersonal relationships. Perceived relationship with managers contributes to job satisfaction while the effects of perceived relationship with colleagues is not significant. The inherent logic may be as follows.

On the one hand, if employees have better relationship with managers who have dominant power and resources in the organization, employees may think that they are more likely to be recognized and appreciated by their supervisors. In that case, they will have a more positive attitude on 
themselves, believing that they not only have the opportunity to get promotion for development but also have more competitive advantages in terms of resource acquisition and benefit rewards. With the help of such a promising expectation, employees' confidence will be strengthened and their psychological pressure may be reduced. Besides, employees may think that they are more likely to be favored and supported by their managers, thus getting more attention and respect from their managers, which is consistent with the findings of previous studies [103]. These findings mirrored those obtained in an earlier published study, which suggested that job dissatisfaction was caused by lack of respect from the supervisor. Previous studies have shown that relationship with supervisors and team leaders plays a more significant role by the way of communication. Different relationship with their managers of leaders may give them the impression that the employees are respected or not [104].

On the other hand, as for the relationship with colleagues, although it may also affect the mood and state of employees at work, its scope of influence may be relatively limited because employees may tend to directly associate the quality of relationship with a specific person rather than the job. In other words, the focus of relationship with colleagues will be put on the individual itself instead of the community. Therefore, the perception of relationships with colleague does not significantly affect job satisfaction as expected.

According to the results of basic regression, we can also find that perceived rationality of compensation has positive effects on job satisfaction while perceived equity does not have such significant effects. Compensation does play a vital role in the job satisfaction. The positive and significant relationship between pay and job satisfaction supports the findings in similar studies [105]. However, the regression results showed that perceived equity of distribution is not so important as the perceived rationality of compensation. One possibility is that the items of perceived equity of distribution in our scale are more inclined to ask their perception of fairness in social level rather than organizational level. Consequently, this measure was not totally accurate and consistent with our research purpose, which is an aspect that needs improvement in future study.

Furthermore, perceived match degree of job and perceived autonomy of work both have positive effects on job satisfaction. When employees feel that their knowledge, skills, and work experience can be effectively used in their existing work, their sense of competency will be effectively met, and they will be driven by their internal motivation to work to achieve their potential and create better performance and higher job satisfaction. In that case, they may think that they are indeed suitable for the current job and can finish related tasks well. This sense of job match can greatly reduce the anxiety and stress that may exist in employees, thereby improving job satisfaction. Findings are consistent with previous research which found that satisfaction in job training is impacted by the perceived compatibility between training knowledge and job requirements [106].

Meanwhile, in terms of job autonomy, the estimation also shows that it is a strong predictor which showed a positive association with job satisfaction. The results indicated that the more autonomy the employees had, the more satisfied they were with their jobs. When employees' perceived autonomy of work is high, it means that employees will have greater flexibility at work, which may reduce the constraints of working hours. Alleviating employees' time conflicts and work schedules can help to better balance work and life, thereby increasing the job satisfaction of employees and making the job satisfaction higher. Employees do not achieve post-training satisfaction because they expect job training to improve job performance, result in salary increase, and ensure promotion [107].

6.1. Quantile Regression Modelling. In order to estimate the influencing factors of job satisfaction in depth, we use quantile regression to conduct the heterogeneity test of different quantile areas.

Quantile regression splits the data into multiple quantile points according to the dependent variable and further estimates the relationship under different quantile points. The main purpose of quantile regression is to analyze the trend of the influence of the independent variable on the dependent variable and to check the robustness of the regression model.

We use the lowest $20 \%$ as the low quantile and the highest $20 \%$ as the high quantile. The analysis results are shown in Table 5 and Figure 2. It can be seen that the $P$ value of RATION is equal to (or less than) 0.05 both in the low quantile and the high quantile $(P \leq 0.05)$, which rejects the null hypothesis and proves that there is a significant difference between the low quantile and the high quantile of perceived rationality of compensation. Besides, the $P$ value of MATCH and AOTON is less than 0.05 in the low quantile $(P \leq 0.05)$, suggesting that compared with the average interviewees, those with lower perception of match degree of job and autonomy degree of work are significantly different. The $P$ value of MANAG is less than 0.05 in the high quantile $(P \leq 0.05)$ and reveals that the perception of relationship with managers is indeed playing a more significant role in job satisfaction when they think they are really having a good connection with managers.

Here we further discuss the very variable that passed the heterogeneity test $(P \leq 0.1)$, namely, perceived rationality of compensation (see Table 6). Since the value of the perceived rationality of compensation is rated in a reverse way, the high quantile interval represents a lower perception of rationality, and vice versa. It can be seen from Table 5 that in the high quantile interval, the results of quantile regression are significantly higher than the results of ordinary linear regression, indicating that ordinary linear regression has a lower estimation of the effects of perceived rationality of compensation. In other words, ordinary linear regression underestimates the impact of perceived rationality of compensation on job satisfaction. Specifically, when the perceived rationality of compensation is low, employees will be more concerned about compensation, so the effects of compensation on job satisfaction become more obvious. In the low quantile range, there exists an opposite situation, especially in the $0.2-0.4$ interval. The results of quantile 
TABLE 5: Quantile regression modelling results.

\begin{tabular}{cccccccc}
\hline & JS & Coef. & Bootstrap Std. Err. & $t$ & $P>t$ & (95\% conf.) & (Interval) \\
\hline \multirow{6}{*}{ q20 } & MANAG & 0.2 & 0.1418238 & 1.41 & 0.159 & -0.0786781 & 0.4786781 \\
& COLLEA & 0.2 & 0.1703923 & 1.17 & 0.241 & -0.1348141 & 0.5348141 \\
& RATION & 0.4 & 0.2037519 & 1.96 & $0.050^{*}$ & -0.0003644 & 0.8003644 \\
& EQUITY & $-1.75 e-16$ & 0.0695895 & -0.00 & 1.000 & -0.1367405 & 0.1367405 \\
& MATCH & -0.2 & 0.0866263 & -2.31 & $0.021^{*}$ & -0.3702173 & -0.0297827 \\
& AOTON & 0.2 & 0.0874006 & 2.29 & $0.023^{*}$ & 0.0282612 & 0.3717388 \\
& _cons & 0.8 & 0.5179869 & 1.54 & 0.123 & -0.2178236 & 1.817824 \\
\hline \multirow{4}{*}{ q80 } & MANAG & 0.4285714 & 0.2065284 & 2.08 & $0.039^{*}$ & 0.0227514 & 0.8343914 \\
& COLLEA & $-7.18 e-15$ & 0.1531282 & -0.00 & 1.000 & -0.3008909 & 0.3008909 \\
& RATION & 0.8571429 & 0.1718596 & 4.99 & $0.000^{* *}$ & 0.5194456 & 1.19484 \\
& EQUITY & -0.1428571 & 0.1041957 & -1.37 & 0.171 & -0.3475976 & 0.0618833 \\
& MATCH & -0.1428571 & 0.0996767 & -1.43 & 0.152 & -0.3387178 & 0.0530035 \\
& AOTON & 0.1428571 & 0.124361 & 1.15 & 0.251 & -0.1015072 & 0.3872215 \\
& _cons & 1.285714 & 0.8899919 & 1.44 & 0.149 & -0.4630844 & 3.034513 \\
\hline
\end{tabular}

Note. ${ }^{*}$ and ${ }^{* *}$ represent the significance level at $5 \%$ and $1 \%$, respectively ( ${ }^{*}$ means $P \leq 0.05 ;{ }^{* *}$ means $\left.P \leq 0.01\right)$.
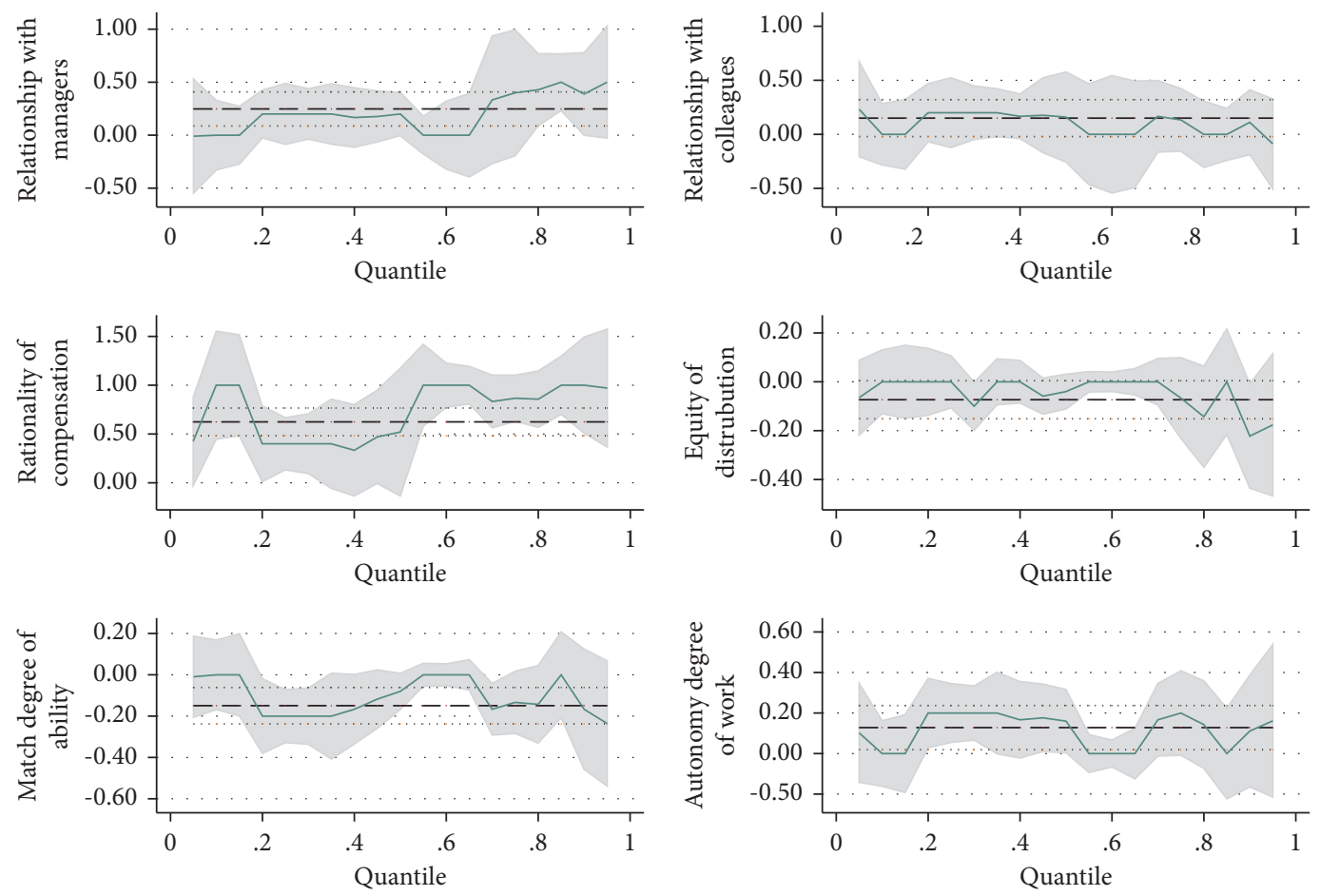

FIGURE 2: Quantile regression interval difference.

TABLE 6: Heterogeneity test: the difference between high quantile and low quantile.

\begin{tabular}{lcccccc}
\hline & MANAG & COLLEA & RATION & EQUITY & MATCH & AOTON \\
\hline$F$ & 1.01 & 0.97 & 3.48 & 1.61 & 0.22 & 0.17 \\
Prob $>F$ & 0.32 & 0.325 & $0.06^{*}$ & 0.21 & 0.64 & 0.68 \\
\hline
\end{tabular}

Note. ${ }^{*}$ represents the significance level at $10 \%{ }^{*}$ means $P \leq 0.01$ ).

regression are significantly lower than those of ordinary linear regression, indicating that ordinary linear regression has a high estimation of the parameters of samples with higher perceived rationality of compensation, that is, ordinary linear regression overestimates the impact of the higher sample of income reasonableness perception. When employees think that their income is reasonable, their attention to income will be reduced, and they may turn to consider career prospects and interpersonal relationships. In other aspects, they may also consider whether their work is in line with their own interests, skills, majors, and experiences. In short, employees with high perception of rationality of compensation may be affected by other incentives rather than compensation. It has been consistent with 
previous studies that regard salary as the most important factor in retaining such staff, who feel that they are not paid sufficiently to reward their particular qualification $[108,109]$.

To sum up, for those with worse perception of compensation rationality, their job satisfaction is more likely to be affected by their compensation while job satisfaction of employees with a better perception of income rationality is relatively less affected by compensation.

\section{Conclusions and Implications}

Based on the sample data of CGSS 2015, we construct a more comprehensive research framework with three dimensions, namely, interpersonal relationship, financial compensation, and work conditions. We analyze the influencing factors of job satisfaction systematically from the perspective of employee's psychological perception. The results demonstrate that perceived relationship with managers, perceived rationality of compensation, perceived match degree of ability, and perceived autonomy degree of work are all significantly positively correlated with job satisfaction. Besides, the effect of perceived rationality of compensation is significantly different between the high quantile and the low quantile. For those with lower perceived rationality of compensation, their job satisfaction is more likely to be affected due to the perceived rationality of compensation than those with higher perception of compensation.

This study sheds light on human resource management in the business practice. First, supervisors should establish proper management modes and use their affinity to interact well with employees. In this way, they can make employees feel themselves in the process of communicating and hold a better perception of interpersonal relationship with managers, thus helping employees to improve their job satisfaction. We recommend that supervisors become more aware of whether and how their behaviors influence employees' job satisfaction. Especially providing specific instructions and using two-way communication seem important to help employees deal with their insecurities and to offer them support. Second, it is important to identify employees' perception of compensation by various ways such as informal communication or questionnaire. As for those employees that regard their compensation unreasonable, it is necessary to adopt corresponding measures to help them realize that the income they receive is in line with their labour commitments or to adjust their compensation of appropriate subsidies, thereby reducing their psychological imbalance and improving employee job satisfaction. Third, managers should pay more attention to employees' characteristics and release the potential of employees by providing employees with a suitable platform and opportunities to match their abilities and fully develop their talents. Fourth, it is essential to give employees appropriate autonomy when arranging work tasks, allowing them to have more flexibility in the work process, thereby increasing employees' satisfaction.

\section{Data Availability}

The data used to support the findings of this study are available from the corresponding author upon request.

\section{Conflicts of Interest}

The authors declare that there are no conflicts of interest regarding the publication of this paper.

\section{Acknowledgments}

This study was supported by the Innovative Research Project of Guangdong University of Foreign Studies.

\section{References}

[1] L. Braham, The 7 Hidden Reasons Employees Leave: How to Recognize the Subtle Signs and Act before It's Too Late, Amacom, New York, NY, USA, 1st edition, 2005.

[2] G. Cai, "Liu Jianxiong. Attribution, autonomy and job satisfaction," Management World, no. 1, pp. 133-142+167, 2013.

[3] C. W. Barrow, "Employee turnover: implications for hotel managers," FIU Hospitality Review, vol. 8, no. 1, pp. 24-31, 1990.

[4] M. R. Testa, "Organizational commitment, job satisfaction, and effort in the service environment," Journal of Psychology, vol. 135, no. 2, pp. 226-36, 2001.

[5] P. C. Smith, L. M. Kendall, and C. L. Hulin, Measurement of Satisfaction in Work and Retirement, Rand McNally, Chicago, IL, USA, 1975.

[6] D. A. Harrison, D. A. Newman, and P. L. Roth, "How important are job attitudes? meta-analytic comparisons of integrative behavioral outcomes and time sequences," Academy of Management Journal, vol. 49, no. 2, pp. 305-325, 2006.

[7] R. Hoppock, Job Satisfaction, Harper \& Row, New York, NY, USA, 1935.

[8] E. A. Locke, "What is job satisfaction?" Organizational Behavior \& Human Performance, vol. 4, no. 4, pp. 309-336, 1969.

[9] A. C. Keith, N. Warshawsky, D. Neff, V. Loerzel, and J. Parchment, "Factors that influence nurse manager job satisfaction: an integrated literature review," Journal of Nursing Management, vol. 29, no. 3, pp. 373-384, 2021.

[10] H. Lu, Y. Zhao, and A. While, "Job satisfaction among hospital nurses: a literature review," International Journal of Nursing Studies, vol. 94, pp. 21-31, 2019.

[11] D. K. McNeese-Smith, "The influence of manager behavior on nurses' job satisfaction, productivity, and commitment," The Journal of Nursing Administration, vol. 27, no. 9, pp. 47-55, 1997.

[12] F. Fu, X. Lu, and Z. Wang, "High satisfaction leads to high performance, or high performance leads to high satisfaction? a 4-year leadership-subordinate pairing study," Psychological Science, vol. 41, no. 4, pp. 897-903, 2018.

[13] I. Huđek, P. Tominc, and K. Širec, "The impact of social and cultural norms, government programs and digitalization as entrepreneurial environment factors on job and career satisfaction of freelancers," Sustainability, vol. 13, no. 2, p. 779, 2021.

[14] G. Hofstede, Culture's Consequences: International Differences in Work-Related Values, Sage, Newcastle upon Tyne, UK, 1984. 
[15] J. Li, R. T. Roessler, P. D. Rumrill, and E. R. Ahmed, "Factors influencing job satisfaction for employed adults with multiple sclerosis," Rehabilitation Counseling Bulletin, vol. 61, no. 1, pp. 28-40, 2017.

[16] J. K. Eskildsen, K. Kristensen, and A. H. Westlund, "Work motivation and job satisfaction in the Nordic countries," Employee Relations, vol. 26, no. 2, pp. 122-136, 2003.

[17] S. You, A. Y. Kim, and S. A. Lim, "Job satisfaction among secondary teachers in Korea," Educational Management Administration \& Leadership, vol. 45, no. 2, pp. 284-297, 2017.

[18] A. E. Clark, "Job satisfaction and gender: why are women so happy at work?" Labour Economics, vol. 4, no. 4, pp. 341-372, 1997.

[19] Y. Luo, "Gender and job satisfaction in urban China: the role of individual, family, and job characteristics," Social Indicators Research, vol. 125, no. 1, pp. 289-309, 2016.

[20] A. E. Clark, "Job satisfaction in britain," Journal of Industrial Relations, vol. 32, no. 4, pp. 189-217, 1996.

[21] L. Chang and W. Kelly, "Individual employment characteristics of hotel employees that play a role in employee satisfaction and work retention," International Journal of Hospitality Management, vol. 29, no. 3, pp. 344-353, 2010.

[22] D. Scott, "Easton, leila dal santo, najwa S safadi, kim hokanson. job stressors and solutions: perspectives of social workers in the occupied Palestinian territories," Human Service Organizations, vol. 43, no. 1, pp. 1-15, 2021.

[23] Y. Xiao and S. Chen, "Increase income or increase the sense of fairness? a survey of job satisfaction of Chinese urban and rural labor," Population and Economy, no. 2, pp. 78-91, 2019.

[24] A. Ijadi Maghsoodi, I. Azizi-ari, Z. Barzegar-Kasani, M. Azad, E. K. Zavadskas, and J. Antucheviciene, "Evaluation of the influencing factors on job satisfaction based on combination of PLS-SEM and F-multimoora approach," Symmetry, vol. 11, no. 1, p. 24, 2019.

[25] R. M. Han, P. Carter, J. D. Champion, Lee, and D. Joseph, "Relationships among factors affecting advanced practice registered nurses' job satisfaction and intent to leave: a systematic review," Journal of the American Association of Nurse Practitioners, vol. 30, no. 2, pp. 101-113, 2018.

[26] T. Penconek, K. Tate, A. Bernardes et al., "Determinants of nurse manager job satisfaction: a systematic review," International Journal of Nursing Studies, vol. 118, Article ID 103906, 2021.

[27] P. Zhou and X. Jiang, "Work pressure and job satisfaction of state-owned enterprise managers: the moderating effect of psychological capital," East China Economic Management, vol. 27, no. 9, pp. 134-137, 2013.

[28] D. V. Jan, "The psychologization of humanitarian aid: skimming the battlefield and the disaster zone Hist," Human science, vol. 24, no. 3, pp. 103-122, 2011.

[29] D. Applebaum, S. Fowler, N. Fiedler et al., "The impact of environmental factors on nursing stress, job satisfaction, and turnover intention," The Journal of Nursing Administration: The Journal of Nursing Administration, vol. 40, no. 7/8, pp. 323-328, 2010.

[30] P. Liu, X. Wang, R. Liu, and W. Xia, "Research on the mechanism of the influence of leadership style on job satisfaction: taking employee relationship as the mediating variable," Chinese Management Science, vol. 21, no. S1, pp. 75-80, 2013.

[31] W. Wu, "The impact of working hours on professional wellbeing: an empirical analysis based on three typical occupations," China Industrial Economics, no. 3, pp. 130$145,2016$.

[32] F. M. Hussien and M. La Lopa, "The determinants of student satisfaction with internship programs in the hospitality industry: a case study in the USA," Journal of Human Resources in Hospitality \& Tourism, vol. 17, no. 4, pp. 502-527, 2018.

[33] Bo Fu, G. Yu, and X. Liang, "The "double-edged sword” effect of the practice of subordinate relationship on employee performance: a cross-level analysis," Scientific Research Management, vol. 40, no. 8, pp. 273-283, 2019.

[34] D. Morton, C. Bowers, L. Wessels, A. Koen, and J. Tobias, "Job satisfaction of registered nurses in a private critical care unit in the Eastern Cape: a pilot study," Health $S A$ Gesondheid, vol. 25, pp. 1-9, 2020.

[35] E. E. Kossek, S. A. Lobel, and A. J. Brown, "Human resource strategies to manage workforce diversity," in Handbook of Workplace Diversity, A. M. Konard, P. Prasad, and J. M. Pringle, Eds., pp. 54-74, Sage, Thousand Oaks, CA, USA, 2005.

[36] S. Alrawahi, S. F. Sellgren, N. Alwahaibi, S. Altouby, and M. Brommels, "Factors affecting job satisfaction among medical laboratory technologists in University Hospital, Oman: an exploratory study," The International Journal of Health Planning and Management, vol. 34, pp. e763-e775, 2019.

[37] M. T. Cardador, G. B. Northcraft, K. W. Rockmann, and B. C. Grant, "Characteristics of affected third parties and cooperative behavior in social dilemmas," The Journal of Social Psychology, vol. 156, no. 6, pp. 565-580, 2016.

[38] M. K. Nalla, S. Y. Paek, and S. S. Lim, "The influence of organizational and environmental factors on job satisfaction among security guards in Singapore," Australian and New Zealand Journal of Criminology, vol. 50, no. 4, pp. 548-565, 2017.

[39] N. Tomaževič and A. Aristovnik, "Factors of trust in immediate leaders: an empirical study in police service environment," International Journal of Environmental Research and Public Health, vol. 16, no. 14, p. 2525, 2019.

[40] P. Hersey and K. H. Blanchard, Management of Organizational Behavior: Utilizing Human Resources, Prentice-Hall, Hoboken, NJ, USA, 3rd edition, 1979.

[41] A. K. Havig, A. Skogstad, M. Veenstra, and T. I. Romøren, "The effects of leadership and ward factors on job satisfaction in nursing homes: a multilevel approach," Journal of Clinical Nursing, vol. 20, no. 23-24, pp. 3532-3542, 2011.

[42] S. P.-p. Choi, S. M.-c. Pang, K. Cheung, and T. K.-s. Wong, "Stabilizing and destabilizing forces in the nursing work environment: a qualitative study on turnover intention," International Journal of Nursing Studies, vol. 48, no. 10, pp. 1290-1301, 2011.

[43] M. A. Van der Wal, J. Schönrock-Adema, F. Scheele, N. R. Schripsema, A. D. C. Jaarsma, and J. Cohen-Schotanus, "Supervisor leadership in relation to resident job satisfaction," BMC Medical Education, vol. 16, no. 1, p. 194, 2016.

[44] L. Stringer, "The link between the quality of the supervisoremployee relationship and the level of the employee's job satisfaction," Public Organization Review, vol. 6, no. 2, pp. 125-142, 2006.

[45] F. Herzberg, "One more time: how do you motivate employees," Harvard Business Review, vol. 46, no. 1, pp. 53-62, 1968.

[46] B. Gilbreath * and P. G. Benson, "The contribution of supervisor behaviour to employee psychological well-being," Work \& Stress, vol. 18, no. 3, pp. 255-266, 2004. 
[47] G. Abekah-Nkrumah and J. Nkrumah, "Perceived work environment and patient-centered behavior: a study of selected district hospitals in the central region of Ghana," PLoS One, vol. 16, no. 1, Article ID e0244726, 2021.

[48] M. M. Sloan, "Gender differences in commitment to state employment: the role of coworker relationships," Public Personnel Management, vol. 46, no. 2, pp. 170-187, 2017.

[49] H. Kroll, T. Macaulay, and M. Jesse, "A preliminary survey examining predictors of burnout in pain medicine physicians in the United States," Pain Physician, vol. 5, pp. E689-E696, 2016.

[50] S. S. Kim, "The effect of social contexts and formation of individualism-collectivism orientation on knowledge sharing intention: the case of workers in Korea," Journal of Knowledge Management, vol. 24, no. 2, pp. 196-215, 2020.

[51] G. Ulrich, A. Homberg, S. Karstens, K. Goetz, and C. Mahler, "Job satisfaction of young professionals in health care," Das Gesundheitswesen, vol. 81, no. 2, pp. 99-105, 2019.

[52] A. Oven and B. Domajnko, "Job satisfaction and creativity at work among occupational therapy practitioners: a mixedmethods study," Work, vol. 69, no. 4, pp. 1351-1362, 2021.

[53] J. F. Volkwein and K. Parmley, "Comparing administrative satisfaction in public and private universities," Research in Higher Education, vol. 41, no. 1, pp. 95-116, 2000.

[54] S. Xu, L. Tao, H. Huang, J. Little, and L. Huang, "Pediatric nurses' turnover intention and its association with calling in China's tertiary hospitals," Journal of Pediatric Nursing, vol. 52, p. e51, 2020.

[55] P. Brough and R. Frame, "Predicting police job satisfaction and turnover intentions: the role of social support and police organisational variables," New Zealand Journal of Psychology, vol. 33, no. 1, pp. 8-18, 2004.

[56] C. B. V. Balinbin, K. T. R. Balatbat, A. N. B. Balayan et al., "Occupational determinants of compassion satisfaction and compassion fatigue among Filipino registered nurses," Journal of Clinical Nursing, vol. 29, no. 5-6, pp. 955-963, 2020.

[57] G. A. Adams and T. A. Beehr, "Turnover and retirement: a comparison of their similarities and differences," Personnel Psychology, vol. 51, no. 3, pp. 643-665, 1998.

[58] M. Cho, "Student perspectives on the quality of hotel management internships," Journal of Teaching in Travel \& Tourism, vol. 6, no. 1, pp. 61-76, 2006.

[59] E. Marinakou and C. Giousmpasoglou, "An investigation of student satisfaction from hospitality internship programs in Greece," Journal of Tourism and Hospitality Management, vol. 1, no. 3, pp. 103-112, 2013.

[60] H. Qu, X. Y. Leung, S. Huang, and J. He, "Factors affecting hotel interns' satisfaction with internship experience and career intention in China," Journal of Hospitality, Leisure, Sports and Tourism Education, vol. 28, Article ID 100311, 2021.

[61] A. Malka and J. A. Chatman, "Intrinsic and extrinsic work orientations as moderators of the effect of annual income on subjective well-being: a longitudinal study," Personality and Social Psychology Bulletin, vol. 29, no. 6, pp. 737-746, 2003.

[62] Z. Wang and H. Jiang, "An empirical study on the influence of individual characteristics of Chinese employees on company satisfaction," Nankai Management Review, no. 1, pp. 101-106, 2004.

[63] M. C. Ellickson and K. Logsdon, "Determinants of job satisfaction of municipal government employees," Public Personnel Management, vol. 31, no. 3, pp. 343-358, 2002.
[64] Y. Ohara, Y. Nomura, Y. Yamamoto et al., "Job attractiveness and job satisfaction of dental hygienists: from Japanese dental hygienists' survey 2019," International Journal of Environmental Research and Public Health, vol. 18, no. 2, p. 755, 2021.

[65] Y. Yang, M. Li, T. Xiong, and H. Song, "The influence of the total remuneration of public institutions in Beijing on job satisfaction-the mediating role of salary fairness," Journal of Beijing Administration Institute, no. 1, pp. 76-83, 2017.

[66] H. Wang, J. Yang, and L. Ye, "Research on the curve mechanism of salary level and job satisfaction," Economics and Management, vol. 41, no. 7, pp. 105-120, 2019.

[67] P. G. Patterson, E. Cowley, and K. Prasongsukarn, "Service failure recovery: the moderating impact of individual-level cultural value orientation on perceptions of justice," International Journal of Research in Marketing, vol. 23, no. 3, pp. 263-277, 2006.

[68] M. Alameddine, M. Baroud, S. Kharroubi et al., "Investigating the job satisfaction of healthcare providers at primary healthcare centres in Lebanon: a national cross-sectional study," Health and Social Care in the Community, vol. 25, no. 6, pp. 1805-1816, 2017.

[69] J. S. Adams, “Towards an understanding of inequity," Journal of Abnormal and Social Psychology, vol. 67, no. 5, pp. 422436, 1963.

[70] U. Hytti, T. Kautonen, and E. Akola, "Determinants of job satisfaction for salaried and self-employed professionals in Finland," International Journal of Human Resource Management, vol. 24, no. 10, pp. 2034-2053, 2013.

[71] O. Dousin, N. Collins, T. Bartram, and P. Stanton, "The relationship between work-life balance, the need for achievement, and intention to leave: m," Journal of Advanced Nursing, vol. 77, no. 3, pp. 1478-1489, 2021.

[72] J. S. Adams, "Inequity in social exchange," Advances in Experimental Social Psychology, vol. 2, no. 4, pp. 267-299, 1966.

[73] M. P. Miceli and P. W. Mulvey, "Consequences of satisfaction with pay systems: two field studies," Industrial Relations, vol. 39, no. 1, pp. 62-87, 2000.

[74] B. Wang, "Research on the relationship between salary fairness, personality traits and job satisfaction," Scientific Research Management, no. 3, pp. 91-100, 2011.

[75] D. McLoughlin and S. C. Carr, "Equity sensitivity and double demotivation," The Journal of Social Psychology, vol. 137, no. 5, pp. 668-670, 1997.

[76] D. Al, A. Mohammed, M. Awais Bhatti, and A. Syah Juhari, Do Psychological Diversity Climate, HRM Practices, and Personality Traits (Big Five) Influence Multicultural Workforce Job Satisfaction and Performance? Current Scenario, Literature Gap, and Future Research Directions, SAGE Open, New York, NY, USA, 2019.

[77] Y. Wang, J. Liu, J. Zuo, and R. Rameezdeen, "Ways to improve the project management efficiency in a centralized public procurement system," Engineering Construction and Architectural Management, vol. 27, no. 1, pp. 168-185, 2019.

[78] W. Lyu, Y. Zheng, C. Fonseca, and J. Z. Zhao, "Public-Private partnership transformation and worker satisfaction: a case study of sanitation workers in H-city, China," Sustainability, vol. 12 , no. 13 , p. $5479,2020$.

[79] A. M. Saks and B. E. Ashforth, "A longitudinal investigation of the relationships between job information sources, applicant perceptions of fit, and work outcomes," Personnel Psychology, vol. 50, no. 2, pp. 395-426, 1997. 
[80] A. Bieńkowska and K. Tworek, "Job performance model based on employees' dynamic capabilities (EDC)," Sustainability, vol. 12, no. 6, p. 2250, 2020.

[81] J. R. Edwards, "Person-job fit: a conceptual integration, literature review, and methodological critique," in International Review of Industrial and OrganIzational Psychology, C. L. Cooper and I. T. Robertson, Eds., vol. Volume 6, pp. 283-357, John Wiley \& Sons, Oxford, UK, 1991.

[82] A. L. Kristof, "Person-organization fit: an integrative review of its conceptualizations, measurement, and implications," Personnel Psychology, vol. 49, no. 1, pp. 1-49, 1996.

[83] M. A. Chilton, B. C. Hardgrave, and D. J. Armstrong, "Person-job cognitive style fit for software developers: the effect on strain and performance," Journal of Management Information Systems, vol. 22, no. 2, pp. 193-226, 2005.

[84] S. Firfiray and M. Mayo, "The lure of work-life benefits: perceived person-organization fit as A mechanism explaining job seeker attraction to organizations," Human Resource Management, vol. 56, no. 4, pp. 629-649, 2017.

[85] J. Luo, Y. Yang, and C. Sun, "Research on the individualorganization matching law of the career growth of female high-level talents in enterprises," Management Review, vol. 30, no. 12, pp. 187-199, 2018.

[86] B. Erdogan, T. N. Bauer, J. M. Peiró, and D. M. Truxillo, "Overqualified employees: making the best of a potentially bad situation for individuals and organizations," Industrial and Organizational Psychology, vol. 4, no. 2, pp. 215-232, 2011.

[87] J. Robst, "Education and job match: the relatedness of college major and work," Economics of Education Review, vol. 26, no. 4, pp. 397-407, 2007.

[88] E. E. Lawler, Strategic Pay, Jossey-Bass, San Francisco, CA, USA, 1990.

[89] A. Zuraik and L. Kelly, "The role of CEO transformational leadership and innovation climate in exploration and exploitation," European Journal of Innovation Management, vol. 22, no. 1, pp. 84-104, 2019.

[90] B. Dai and B. Akey-Torku, "The influence of managerial psychology on job satisfaction among healthcare employees in Ghana," Healthcare, vol. 8, no. 3, p. 262, 2020.

[91] J. R. Hackman and G. R. Oldham, "Development of the job diagnostic survey," Journal of Applied Psychology, vol. 60, no. 2, pp. 159-170, 1975.

[92] M. I. Loft and C. S. Jensen, "What makes experienced nurses stay in their position? A qualitative interview study," Journal of Nursing Management, vol. 28, pp. 1305-1316, 2020, http:// gfzgf7f12bbd3c09549a1s99060wvkwnwk6n0f.fxbh.librra.gd ufs.edu.cn/10.1111/jonm.13082.

[93] Y. Jo and L. T. Hoover, "Source of job satisfaction among South Korean police officers," International Journal of Police Science and Management, vol. 14, no. 2, pp. 136-153, 2012.

[94] A. B. Bakker and E. Demerouti, "The job demands-resources model: state of the art," Journal of Managerial Psychology, vol. 22, no. 3, pp. 309-328, 2007.

[95] F. P. Morgeson and S. E. Humphrey, "The Work Design Questionnaire (WDQ): developing and validating a comprehensive measure for assessing job design and the nature of work," Journal of Applied Psychology, vol. 91, no. 6, pp. 1321-1339, 2006.

[96] S. Mohammed and L. C. Angell, "Surface- and deep-level diversity in workgroups: examining the moderating effects of team orientation and team process on relationship conflict," Journal of Organizational Behavior, vol. 25, no. 8, pp. 1015-1039, 2004.
[97] J. Liu, C. Liu, and R. Liu, "Research on the performance of flexible working hours of employees in high-tech enterprises: a mediation model based on work autonomy," Science and Technology Management Research, no. 19, pp. 119-124, 2015.

[98] L. Luo and X. Zhou, "Overtime, workload autonomy and utility on the existence of working hours constraints," Economic Trends, no. 3, pp. 59-73, 2019.

[99] L. Tian, "The five-dimensional exogenous cause of job satisfaction: which is more important?" Foreign Economics and Management, vol. 41, no. 9, pp. 75-90, 2019.

[100] M. Wu, Y. Yang, and X. Wang, "The impact of flexible work plans on employee psychology and behavior: a meta-analysis test," Economics and Management, vol. 42, no. 7, pp. 126$140,2020$.

[101] K. Namasivayam and X. Zhao, "An investigation of the moderating effects of organizational commitment on the relationships between work-family conflict and job satisfaction among hospitality employees in India," Tourism Management, vol. 28, no. 5, pp. 1212-1223, 2007.

[102] M. Deery and L. Jago, "Revisiting talent management, worklife balance and retention strategies," International Journal of Contemporary Hospitality Management, vol. 27, no. 3, pp. 453-472, 2015.

[103] L. L. Andersen, D. Fishwick, E. Robinson, N. M. Wiezer, Z. Mockałło, and V. Grosjean, "Job satisfaction is more than a fruit basket, health checks and free exercise: cross-sectional study among 10,000 wage earners," Scandinavian Journal of Public Health, vol. 45, no. 5, pp. 476-484, 2017.

[104] D. M. Harmening, B. M. Castleberry, and M. E. Lunz, "Technologists report overall job satisfaction: 10-year retrospective study examines career patterns," Laboratory Medicine, vol. 25, no. 12, pp. 773-775, 1994.

[105] L. Lum, J. Kervin, K. Clark, F. Reid, and W. Sirola, "Explaining nursing turnover intent: job satisfaction, pay satisfaction, or organizational commitment?" Journal of Organizational Behavior, vol. 19, no. 3, pp. 305-320, 1998.

[106] C. A. O'Reilly and J. Chatman, "Organizational commitment and psychological attachment: the effects of compliance, identification, and internalization on prosocial behavior," Journal of Applied Psychology, vol. 71, p. 492, 1986.

[107] M. Nedeljković Knežević, M. D. Petrović, S. Kovačić, M. Mijatov, D. B. Vuković, and J. Kennell, "Acting the part: emotional intelligence and job satisfaction as predictors of emotional labor in travel agencies," Tourism and Hospitality Research, vol. 21, no. 2, pp. 183-201, 2021.

[108] K. Doig and S. Beck, "Factors contributing to the retention of clinical laboratory personnel," Clinical Laboratory Science: Journal of the American Society for Medical Technology, vol. 18, no. 1, pp. 16-27, 2005.

[109] A. Yami, L. Hamza, A. Hassan, C. Jira, and M. Sudhakar, "Job satisfaction and its determinants among health workers in Jimma University Hospital," Ethiopian Journal of Health Science, vol. 21, no. 1, pp. 19-27, 2011. 